\title{
Chernobyl \& Fukushima: Lessons to be Learnt
}

\author{
Pradeep Purushottam Sharma
}

Published online: 7 April 2011

(C) Association of Surgeons of India 2011

"The discovery of nuclear chain reactions need not bring about the destruction of mankind anymore than did the discovery of matchsticks. We only must do everything in our power to safeguard its abuse." Albert Einstein

Murphy's Law: If something can go wrong, it will.

This article comes at an appropriate time because of two reasons:

First, recently, subsequent to a massive earthquake followed by tsunami, a meltdown in Fukushima Dai-chi Nuclear reactor led to an explosion. This explosion has caused a havoc not only in the Japan, but also in the neighboring countries like Korea, Russia etc. Till date, there have been more than 17,000 deaths and probably an equal number missing.

Second, India, too, is looking at Nuclear reactors as an energy source. Recently, there has been, and it still continues, a lot of controversy regarding the erection of Nuclear power plants at Jaitapur in Maharashtra and Kovvada in Andhra Pradesh and this has evoked a lot of controversy on the front pages of all the newspapers. The Government is trying armtwisting measures to contain the dissentment in the minds of the people who would be unsettled as a result of this plant. Since radiation has immediate as well as long term effects (disastrous) on mankind, and since we, the medical fraternity,

P. P. Sharma ( $\square)$

Noble Hospital \& Research Centre,

Division of GI, Laparoscopic and Endocrine Surgery,

Hadapsar Kharadi Bypass Road,

Pune 411013, India

e-mail: drpradeepsharma@gmail.com would be looking after this affected population, we have to be aware of its hazards.

Let us first see why we have to seek energy from nuclear reactors. Power is the backbone of any economy; be it a developed or a developing country. As far as power production is concerned, our situation is similar to that of Japan. We do not have underground oil (unlike the Arab world) and have limited coal and underwater gas, which is grossly insufficient for a large Indian economy. We have plenty of water (network of rivers across the country) but for reasons unknown and for the lack of political vision, it has been largely under-utilized. That brings nuclear energy from the nuclear plants into play. Presently, nuclear energy contributes to a measly $3 \%$ of the country's power supply and it is estimated that it would increase to $6 \%$ by 2020 and $13 \%$ by 2030 . Till date the United States has 104 nuclear reactors that generate $20 \%$ of the nation's energy and they are in the process of building 20 more in the coming years.

Nuclear energy was considered to be a gift to the mankind till 26th April 1986, when the world's worst disaster, the Chernobyl explosion, occurred in Russia, leading to a large number of casualties, the aftermath scars of which are still seen today.

Today this incident has taught us a very important lesson: We, till date, do not have control over natural disasters like the earthquake, tsunami etc, but we can avoid incidents like the Chernobyl and Fukushima.

Chernobyl Disaster: The disaster caused 31 immediate fatalities from Acute Radiation Sickness and nearly 6,000 deaths from excess cancers due to radiation exposure. More than 6,000 cases of Thyroid cancers attributable to the explosion have been noted. Moreover almost 4,000 square kilometers of land is now uninhabited with 120 villages and 
two major cities left to decay. Almost 1, 35, 000 people have lost their homes- a huge price the nation and mankind had to pay.

The radiation released was so massive that the radioactive contaminants were seen almost globally. The radiation reached far off countries like the US across the Pacific but the levels were too low to cause any hazards. Some studies of the health effects are still underway as some effects may occur after years and decades. Preliminary studies showed a high incidence of thyroid cancers, leukemia's and other hematological malignancies. Sadly, the worst affected were the children and adolescents, since the thyroid gland is active in the young and can absorb large amount of radio iodine. Also the young have a long life ahead so late manifestations can surface later in life.

Exposure to the high dose of radiation can cause a range of health effects called Acute Radiation Syndrome (ARS) which can manifest from simple diarrhea to deadly cancer. Mild exposure (1 sievert) may not have any symptoms. Nausea, vomiting and skin damage often begins within hours of moderate exposure ( 2 to 3.5 sievert) followed by diarrhea, headaches, fatigue, lassitude and fever. The vomitus and stools may contain blood due to damage to the intestinal lining. After the first round of symptoms have subsided, there may be a lull lasting few weeks to years (Chronic Radiation Syndrome) when damage to the internal organs manifests. The radiation can destroy the bone marrow leading to aplastic anaemia, internal bleeds and intercurrent infections. Only extremely high dose of exposure can cause rapid death. Radiation exposure also increases the possibility of developing other diseases like cancers and genetic damages. These effects, thus, are passed on to the subsequent generations. Mortality with upto 6 to 8 sievert exposure is about $50 \%$ whereas exposures over 30 sieverts are associated with $100 \%$ mortality.

One of the radiation hazards is that to the Thyroid gland, since there is a large amount of Radioactive Iodine 131 in the effluents. Radioactive materials can go to far off places through food like milk, milk products and leafy vegetables (Many countries have banned imports from Japan) and water (Government has asked people to avoid using tap water). Some airborne exposure can also occur when the nuclear fuel burns and the smoke liberated is carried by the wind currents. Radio iodine 131 also has a tendency to stick to the soil and contaminate the ground water as well as vegetables growing in the soil all of which can remain contaminated for months and even years. Large doses can destroy it leading to Hypothyroidism (similar to the radio iodine treatment after Total thyroidectomy) while lesser dose may cause cellular damage and elicit a carcinogenic response in the form of Differentiated cancers of the thyroid. Oral potassium iodide taken immediately before or after such exposure may prevent damage to the gland by competing with the radioactive iodine. So much was the hype in the media about this, that it resulted in a mad indiscriminate rush and hence acute shortage of this medicine.

Other radioisotopes released include Cesium 134, Cesium 137 and Strontium 90. Strontium can compete with calcium for absorption into the bones thereby leading to brittle bones.

Japan is a developed nation and hence the nuclear industry is highly regulated. The workers in this industry are carefully monitored for their radiation exposures. The average exposure of a worker over 12 years is 25.7 millisieverts. (For comparison, a whole body CT scan would expose an individual to 12 millisieverts of radiation). Millisieverts is a unit of radiation used to measure a dose averaged over all tissues of the body and is used to monitor the penetrating gamma radiations in workers. The Chernobyl disaster exposed the workers to average 76.4 millisieverts of radiations.

Disasters and calamities have always plagued the mankind since times immemorial. Earthquakes, floods, tsunami, typhoons, epidemics, hurricanes etc have claimed thousands of lives across the globe. Contingencies and safeguards cannot be guaranteed especially against such extremely powerful natural disasters. However, nuclear disaster differs in the sense that it is manmade disaster. Yet, we have to build and rebuild, defy the risk and accept the consequences as this is the necessity of an expanding population. And when the growth of population is very high like ours the stakes are equally high.

In other words, if we are to survive, we have no choice but to continue to play the game. BUT THE LEAST WE CAN DO IS PLAY IT SAFE. So let NO CHERNOBYL AND FUKUSHIMA HAPPEN AGAIN. Very simple things, like building it away from the rivers and coastlines and from the active seismic zones. Remember that Technology has its own inherent risk. More the sophistication more is the risk.

We, as Medical fraternity, have double responsibility. To take care of the human health and as a part of general population we too are exposed to all the hazards of radiation.

LET US HOPE THAT THE RADIATION WHICH IS A BOON FOR OUR CANCER PATIENT, DOES NOT BECOME A BANE FOR THE MANKIND.

Hence we have to be alert and vigilant. 